FERNANDO M. VARELA

\title{
EL HUMOR EN LA ESCULTURA DE JUAN DE DIOS MENA
}

Hay artistas que poseen una vocación metafísica, que han descubierto la distancia existente entre la superficie de los seres y lo que ellos son profundamente, para luego desenmascarar la realidad cotidiana. Ellos revelan y obligan a percibir lo esencial, y su obra, aunque cuando de una fascinante verdad, inquieta, suscita la sorpresa y la presencia de otra existencia.

A ese grupo de artistas pertenece Juan de Dios Mena, un escultor cuyas imágenes sirven de vehículo a una fuerza interior, a un deseo de cambiar la vida. El ha visto lo que nosotros dejamos de percibir, porque miraba desde afuera, en observador; asombrado frente al espectáculo de lo humano, intentó encontrar un sentido a la vida; sus preguntas son tan intensas que desalientan toda respuesta; su ingenuidad es tan enorme que destruye las convenciones. Su escultura, humorística al primer contacto -porque nuestra reacción al desafío de la existencia es el reír-, se vuelve angustiosa y patética, y si reflexionáramos un poco, nos sorprenderíamos de haber podido tomarla con superficialidad.

Juan de Dios Mena nació en Puerto Gaboto, provincia de Santa Fe, en 1897. Miembro de una familia modesta y numerosa, desempeñó desde pequeño tareas honestas; ya adulto, trabajó un tiempo en la ciudad de Rosario en el Escuadrón de Seguridad, nombre que se daba en ese entonces a la policía montada. Después viajó a Buenos Aires, donde lo encontramos trabajando en la revista "Nativa", escribiendo versos, ocupación que compartía con la de cobrador para poder subsistir. La vida ciudadana, sin embargo, no lo satisfacía, y siempre sintió una profunda nostalgia por el campo. Así fue como se vinculó en la Capital con un señor de apellido 


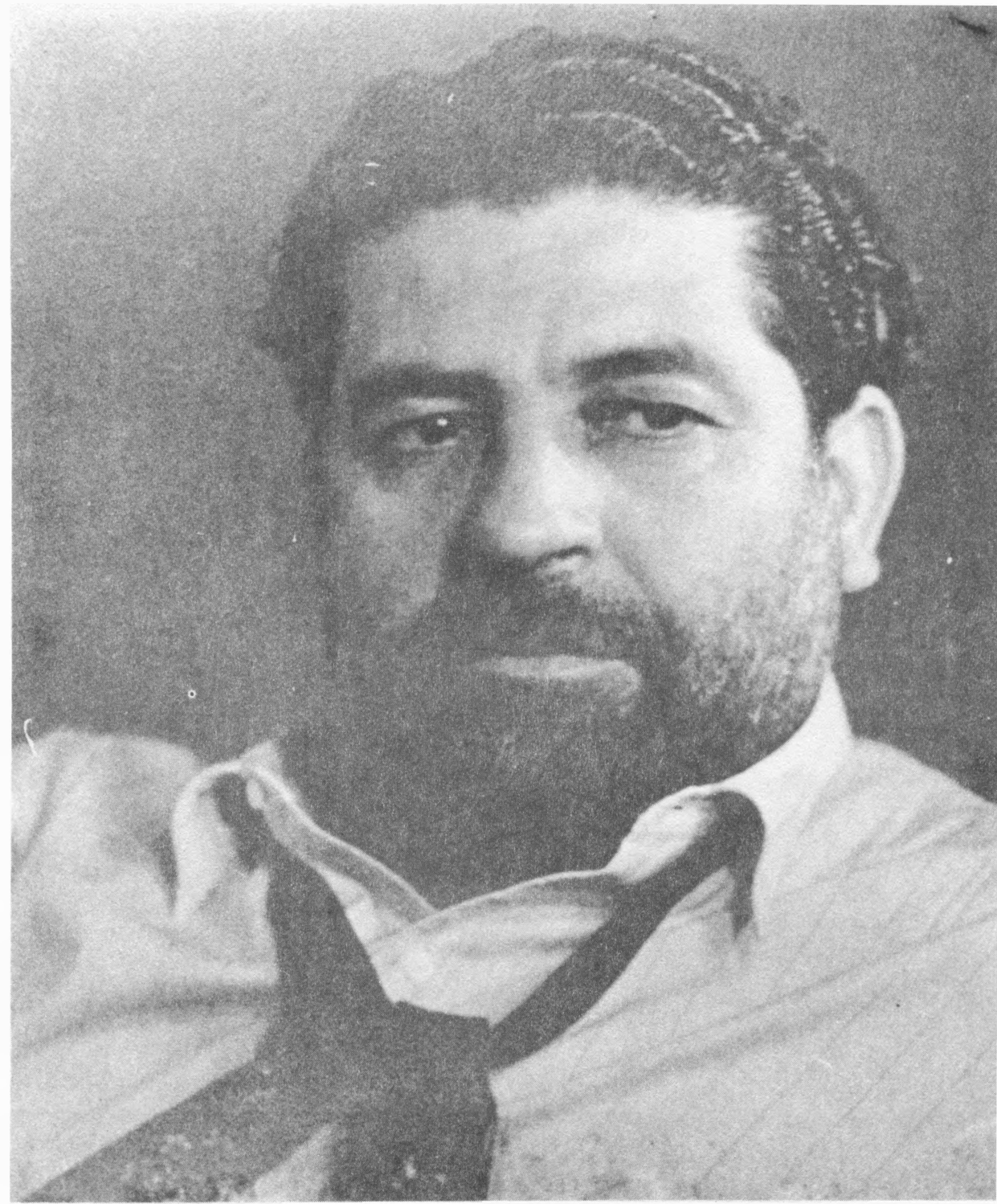

1. Juan de Dios Mena.

Tallas: Colección El Fogón de los Arrieros. Fotografías: José Iturri. 
Gahn, terrateniente, quien lo invitó a hacerse cargo de uno de sus campos, primero en el norte de Santa Fe y luego en Colonia Baranda, provincia del Chaco. Fue en esta localidad donde, hacia 1932, se descubre habilidades para la talla, cuando un paisano amigo suyo le regala una estaca de guayaibí, madera dura de la región, para que hiciera con ella un bastón. Mena tomó un cortaplumas con el propósito de hacer una calavera para el mango, pero el resultado fue la cabeza de un paisano. Ya se vislumbra allí la fuerza de lo inconsciente que existe en toda creación y que llevará al propio artista a reconocer como característica de su obra, al confesar a un periodista: "Mis figuras tienen su propia personalidad. A veces les doy una intención que no se me ocurría al principio. Se me escapa el cortaplumas, ¿sabe?, y hace de las suyas ..." "(1)

Esta primera talla tosca, pero expresiva, fue el punto de partida de su carrera de escultor. Posteriormente encontrará la madera del "curupí" (2), que será desde entonces el material utilizado por su imaginería. Fue por esta época que Gahn ofrece a Mena el ocuparse del bar "Florida" de la ciudad de Resistencia; allí hará amistad con las figuras inquietas del quehacer cultural chaqueño. Del "Florida" pas6́ al bar "América", trabajo que luego abandonó para dedicarse únicamente a la escultura. En 1937 conoce a Aldo Boglietti y forma parte del grupo denominado "Los Bagres" que se reunía alrededor del doctor Alberto Torres y del entomólogo francés Pedro Denier, en el restaurante "Chanta Cuatro", para discutir sobre temas literarios y de actualidad. La amistad con Aldo Bo. glietti se irá consolidando al paso de los años y en 1944, deciden compartir la casa que éste alquilaba en Brown 188, donde nace el primitivo "Fogón de los Arrieros"; Mena no dejará el lugar hasta su muerte, en abril de 1954. Este hombre andariego e inquieto pasó allí diez años de su vida, sustentándose con la venta de sus esculturas, llevando una existencia modesta de acuerdo con su carácter. Su tiempo transcurría allí de una manera ordenada, en la que la talla alternaba con sus otras actividades predilec. tas: la pintura y la poesía. Su libro "Virolas y otras chafalonías", aparecido en 1931, había merecido el elogio discreto de la crítica.

La escultura fue, sin embargo, su gran pasión, allí halló una manera plástica de expresarse y de comunicar a sus semejantes lo que sentía. Este hombre sin educación -sólo concurrió a la escuela primaria hasta tercer grado-, fue un autodidacta que aprendió a enfrentarse con la materia y con los problemas de la forma, con la ayuda de herramientas rudimenta. 


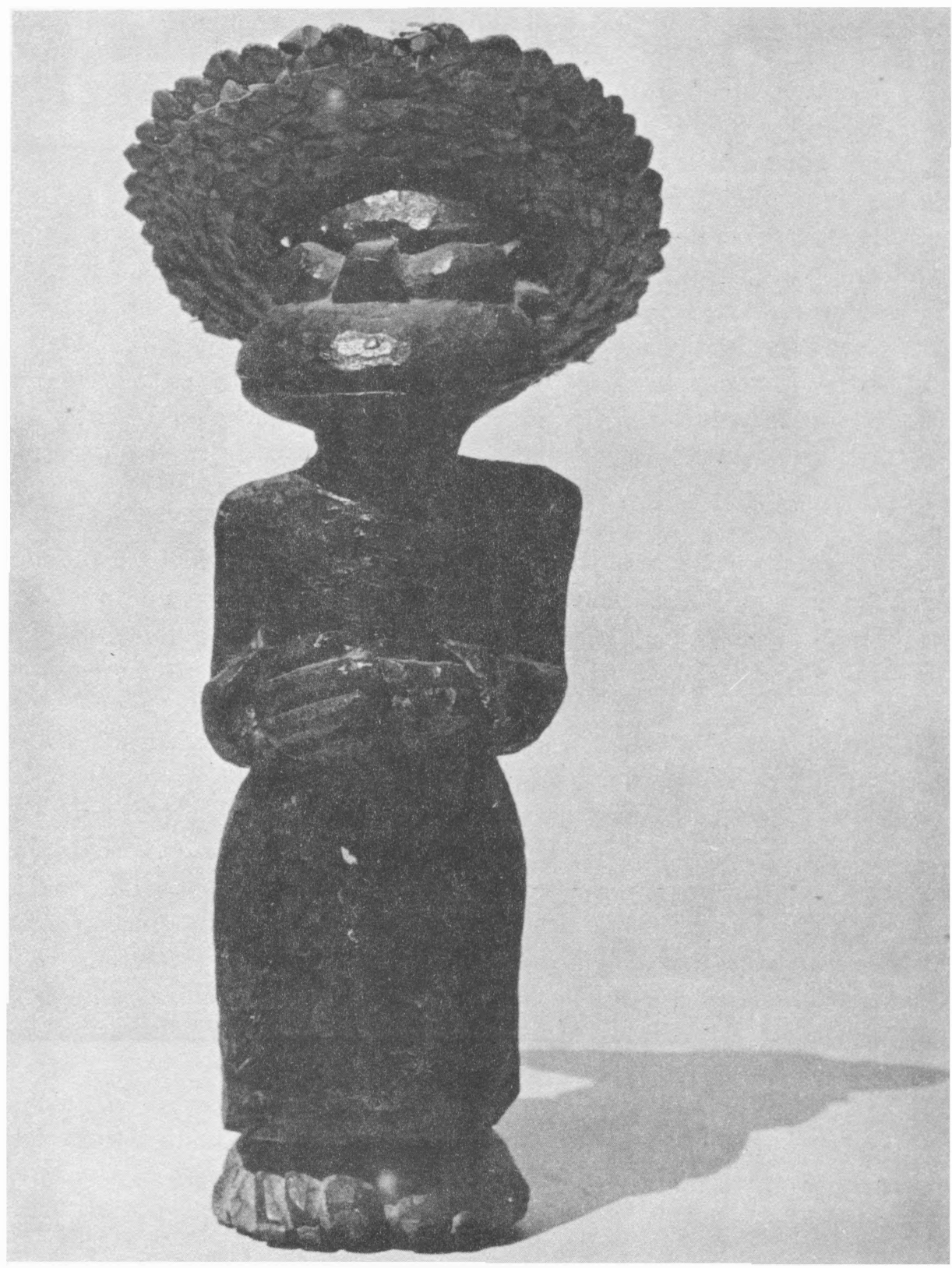

2. Figura (primera época) 
rias: un cortaplumas, un cuchillo, un machete. Sin calcular la trascendencia de su labor, comenzó modestamente la creación de sus muñecos, para su propia satisfacción. Sus primeras obras contaban con accesorios: trozos de tela, postizos de crin, sombreros de paja; ellas mueatran una cierta rigidez (fig. 2) que nos habla de las primeras dificultades del artista para lograr el dominio de la talla. Su técnica, sin embargo, evoluciona rápidamente, y entre su primera exposición organizada en 1936 en Buenos Aires, en la galería Müller de la calle Florida, y su participación, cuatro años después, en la muestra que el Chaco organizó en la Sociedad Rural de esa ciudad, hay una neta madurez expresiva.

Sus esculturas, notables por la gracia y originalidad, nacen del talento de Mena para localizar en los personajes que conoce, los gestos inconscientes inevitables, para reproducirlos después. Su "gente", como él los llamaba, pertenecen a una temática eminentemente argentina: ya sea cuando se ocupa de los usos y costumbres camperos, o de los tipos ciudadanos ya consagrados por el tango, o de sus incursiones en lo histórico, con la representación de indios y gauchos federales; y aún cuando su arte aborda lo religioso, el resultado son esos incomparables Cristos criollos (fig. 7). Pero si bien sus tipos son regionales, la problemática que plantean es universal, ya que hay en ellos una comprensión más objetiva de la naturaleza humana, que lejos de escondernos el modelo, nos lo muestra más vivo, más despojado de sus contingencias. Para lograrlo, el artista extrae de los seres y de las cosas que observa, la expresión intima, y este espejo fiel que nos tiende con humor y de manera insolente, es un espejo deformante: él exagera, distorsiona, estiliza, para mejor expresarse, en un admirable dominio de la síntesis.

En "Doma" (figs. 3 y 4) vemos en qué consiste la esencia de su obra: por una parte, un contrapunto de líneas, masas y perspectivas que se vinculan con lo estético, y por otra, una disonancia desvalorizadora que la vuelve risible. Sobre un caballo de cuerpo arqueado, con la cabeza clavada en la tierra -donde los orificios desmesurados del hocico y la mirada fija de los ojos, indican un esfuerzo muscular y colérico-, se ve un domador que parece concentrar todas sus energías en mantenerse montado: sus botas con grandes espuelas permanecen pegadas al cuerpo del animal, mientras que sus manos fijas en las riendas vuelven innecesario el talero. Su cuerpo pequeño parece hundido en el lomo del caballo y, visto de frente, se reduce únicamente a la cabeza, dominada por unos ojos globulosos y 


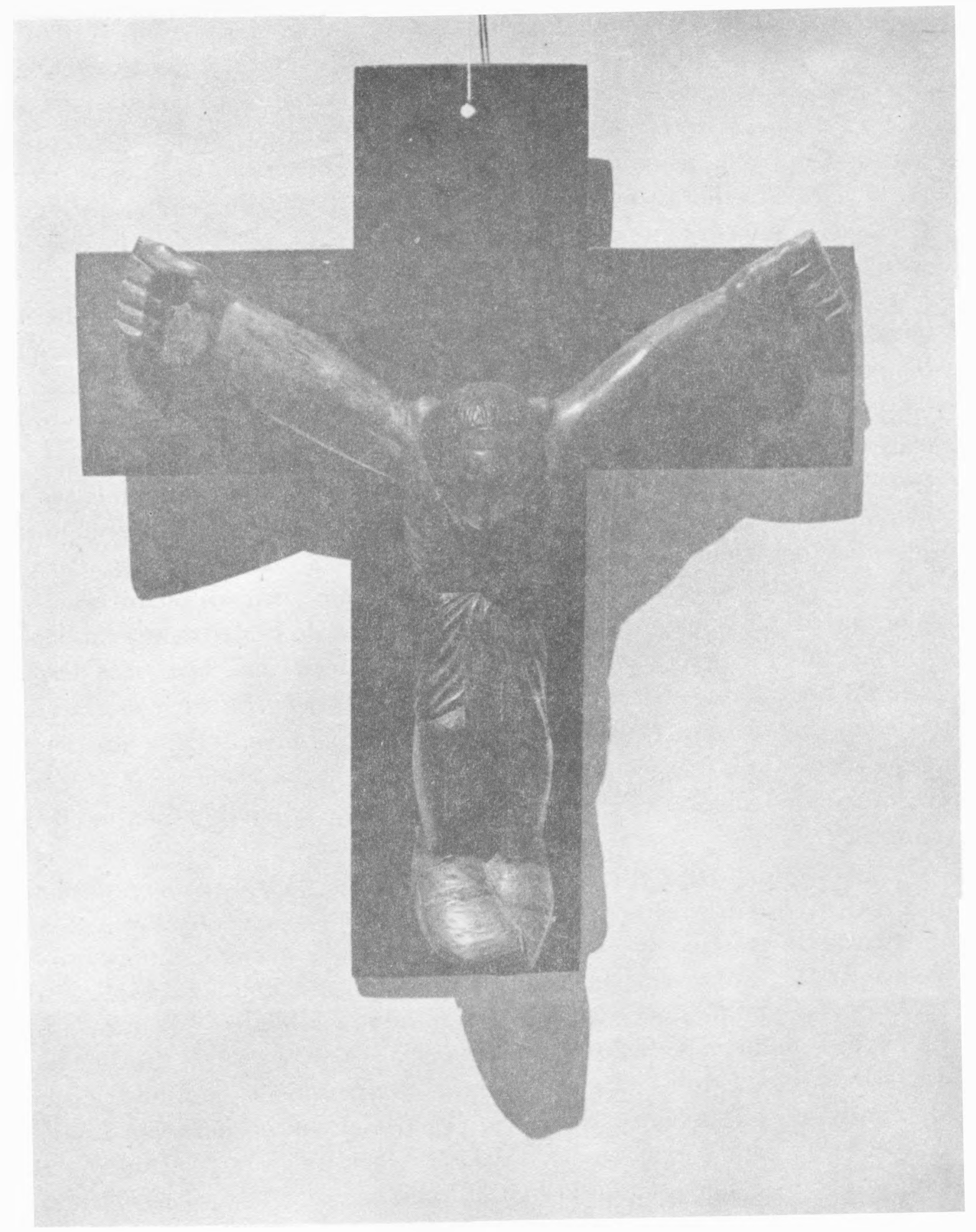

3. Cristo. 

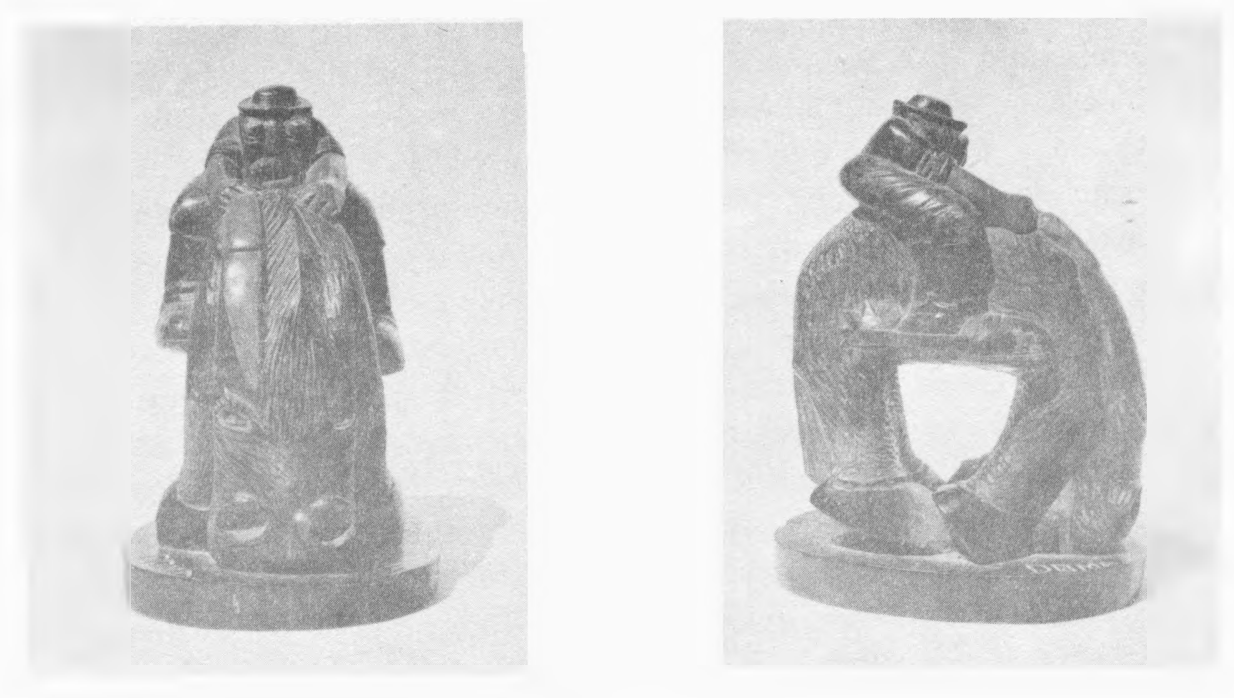

4-5. Doma.


6- 7. Patos. 
saltones que junto al rictus de la boca, indican el momento psicológico provocado por el trance difícil de la doma. Esta es, como la mayor parte de las pieza de Mena, una imagen real, concentrada y sabiamente exagerada, que no recuerda que la mímica constituye una forma satírica esencial. Algo similar notamos en otra de sus obras, titulada "Patos" (figs. 5 y 6), en la que representa a un cazador en acción. El artista ha hecho de los pies casi cuadrados y desmesuradamente grandes para indicar un andar cauteloso. Las manos, también enormes, toman con firmeza un trabuco de doble caño que, plegándose en movimiento significativo al cuerpo del hombre, parece participar también de la espera. Como contrapunto el cazador tiene una cabeza pequeña pero intensa en expresión, donde los ojos de mirada inquieta, exasperada, están dirigidos al cielo como esperando la aparición de la presa. Aquí la sonrisa es causada por estímulos que no son cómicos en sí mismos, sino indicios o símbolos representados por patrones humorísticos establecidos, tales como la medida de los pies o la pequeñez del sombrero que continúa las líneas de una cabeza de forma cónica.

Toda la imaginería de Mena se basa en una cierta bonomía que se manifiesta en la elección de las posibles combinaciones que nos pueden hacer reír, todas surgidas del medio o provocadas por él: situaciones embarazosas, contraste entre las funciones y quienes las representan, y toda una turbadora variedad de disposiciones de ánimo comprendidas en diferentes formas de humorismo, pero que contienen un ingrediente básico indispensable: un impulso de agresión o de aprensión que puede aparecer disfrazado de malicia, desdén o condescendencia hacia la víctima de la broma. En el caso de "Diputado" (figs. 8 y 9), vemos al hombre político observado con los ojos del pueblo. Todos los recursos expresivos están dirigidos aquí para lograr una imagen del ciudadano -corte de cabello y uñas cuidadas-, que inspira poca confianza. Sentado frente a un pocillo de café, en actitud pensativa lindando con el aburrimiento, vemos al diputado con su gran boca ladeada, encuadrada por una mano fuera de toda proporción. Y si su boca es grande de tanto hablar, sus orejas lo son para mostrarnos que puede oírlo todo. Aquí el artista ha exagerado los rasgos que considera más característicos, suavizando el resto.

¿Cuál es nuestra reacción delante de las escenas que Mena hace jugar a sus personajes: En un primer momento nos parece que eso no nos concierne, estamos bajo la impresión de que es algo gratuito, porque nuestra 


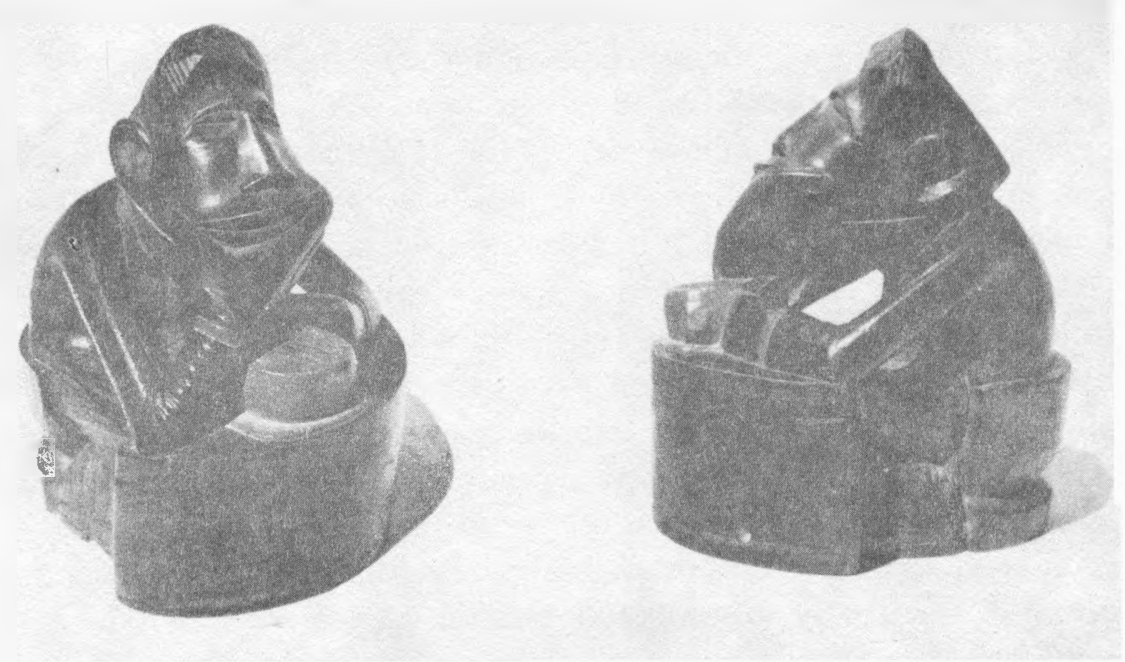

8-9. Diputados.

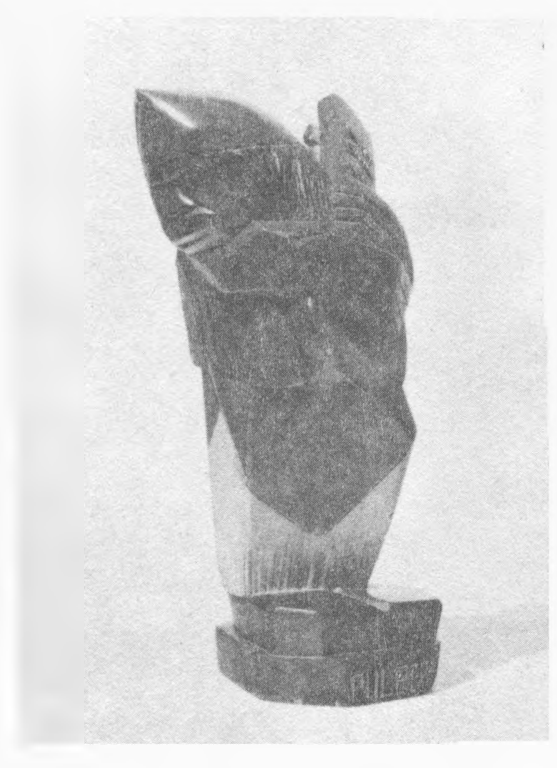

10. Gaucho Federal.

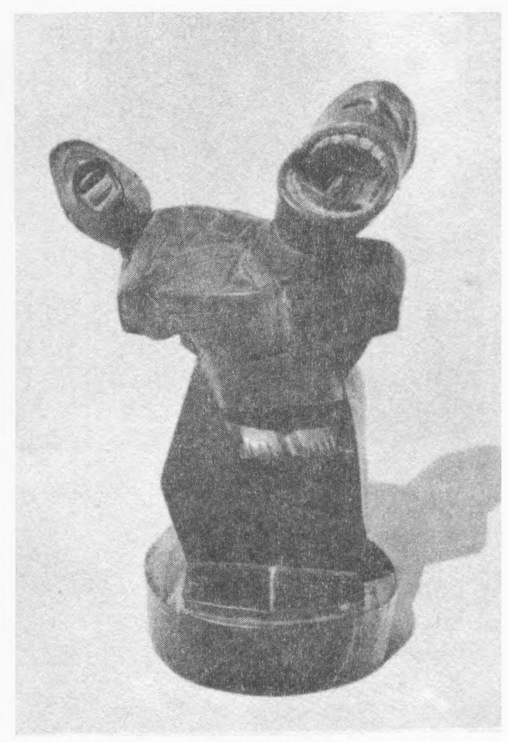

11. Llanto. 
atención sólo enfoca un detalle arrancado del contexto funcional del cual dependía su significado ; para poder reír es necesario olvidar momentáneamente la dramaticidad de la vida, que sólo es cómica en sus detalles. Pero cuando comprendemos esto, el reír se fija, dejando lugar a la angustia que produce lo inhumano. Mena había comprendido esta actitud paradójica del hombre frente a la existencia, cuando confesó: "Los muñecos viven el drama de los hombres. Yo que soy profundamente triste, como todo humorista, asomo a las expresiones de ellos, todo cuanto ocultamos o decimos." (3) Esta actitud suya participa de la polarización inestable que es ley de toda vida afectiva: es sentimental y razonada, entusiasta y fría, real y fantástica, optimista y pesimista. Y a través de ella, este artista autodidacta, intuitivo, guiado por su fuerte sensibilidad y una inteligencia vivaz, realizó toda una obra original para revelarnos la existencia del absurdo en lo familiar, y dejarnos una imagen del mundo que hubiera deseado cambiar. "Ce noonde que la comédie met en scène, mieux vaudrait qu'il ne fût pas."

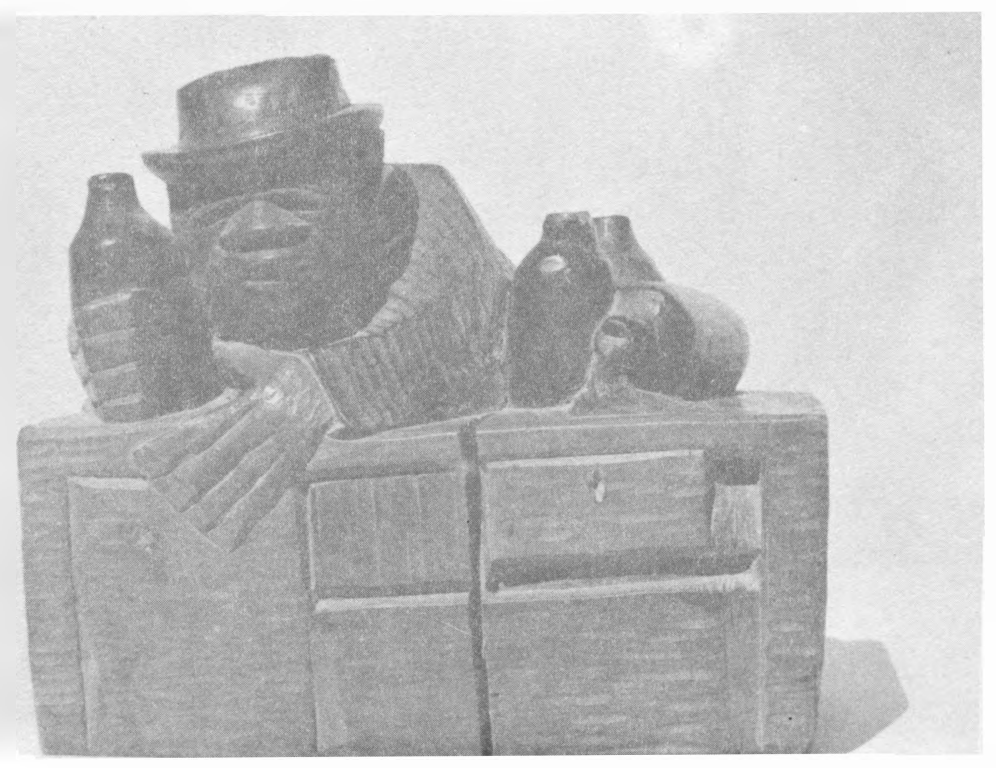

12. Mostrador. 




13. Figura (última época). 
(1) Alvera (M.), "Los tapes del gaucho Mena", in Aqui Está, Buenos Aires, Año XI, № 1056, 1946, pág. 20.

(2) Nombre vulgar del Sapidum Haematospermun, llamado también "palo de leche" o "lecherón". Arbol de regiones tropicales, de hojas brillantes y corteza rugosa; de su tronco se extrae un jugo lechoso semejante a la goma elástica, mientras que su madera es desdeñada por liviana para el fuego y blanda para la construcción. El color de esta madera va del blanco rosáceo al castano y, debido a su característica "pastosidad" es fácil de tallar.

(3) Garcia Hernández (M.), “Los muñecos humanos de Juan de Dios Mena", in El Pueblo, Resistencia, 16 de enero de 1941. 


\section{BIBLIOGRAFIA}

ALVERA (M.),

BENAVENTO (G. L.),

CASTANY (E.),
"Los tapes del gaucho Mena", in Aqui Estć, Buenos Aires, Año XI, N• 1056, 1946.

"Productos del Chaco: Versos. Una visita de inspección por la fábrica de Juan de Dios Mena", in Estam. pa Chaquenta, Resistencia, s./f.

"Juan de Dios Mena: labrador del Curupt, in El Clarín, Buenos Aires, $1^{\circ}$ de febrero de 1948.

CORDOVA ALSINA (M. A.), "El nombre de Juan de Dios Mena al curupí", in Democpacia, Buęnos Aires, 10 de abril de 1955.

CORDOVA ITURBURU (C.), "El recuerdo permanente de J. D. Mena", in El Clartm, 4 de septiembre de 1955.

CORDOVA ITURBURU (C.), SQUIRRU (R.), Mena, Resistencia, El Fogón de los Arrieros, 1961.

GARCIA HERNANDEZ (M.), "Los muñecós humanos de Juan de Dios Mena", in El Pueblo, Resistencia, 16 de enero de 1941; artículo reproducido en Diario de la Marina, La Habana (Cuba), 25 de mayo de 1941.

MARTELLI (S. C.),

MURUA (P. O.),

VILLANUEVA (A.),
"Los ciudadanos de madera de Juan de Dios Mena", in La Nación, Buenos Aires, 13 de abril de 1941.

"El arte de Juan de Dios Mena", in La Capital, Rosario, 13 de julio de 1941.

"Juan de Dios Mena talla en el Social", in El Litoral, Santa Fe, 1944. 